mating with first or second cousins rather than outsiders. An interesting sidelight is given by Jakobi and Darlu whose paper on Mating Patterns in Isolates considers the POG. This is the Probability of Origin of Genes in latter generation members of the isolate. I had not appreciated how variable the contribution of the founders could be, and how small, given even a very few outside marriages.

Several papers look at the role of geographical, social, and cultural factors in mate choice. The authors occasionally go to some trouble to prove things I thought I knew already: that you are more likely to marry someone from down the road than someone from over the hill and far away, or that poor girls who wish to marry rich men should be beautiful. Perhaps those who understand more of the subject appreciate details which escaped me. Assortative mating is considered by several authors, with useful data on physical and psychological traits. A more difficult question is whether different degrees of assortative mating are associated with differential fertility. Here the evidence is inconclusive except for years of schooling, which has a low genetic content.

In summary, reading this book probably won't answer your questions about the different mating patterns now seen in important parts of the British population. It will show you what biological anthropologists do, and give numerous curious titbits of information. The paper I most enjoyed had nothing to do with genetics. This was an elegant exposition of the connection between romantic love, capitalism, and the demographic transition. If you won't let your family choose your spouse, then you can't expect them to support you when you marry. Therefore you must accumulate your own wealth and delay marriage until you can afford it. You can make more money when single, so those who value money above love never marry. All this means fewer children and less need for war, famine, or pestilence to keep the numbers down. I am not sure whether it is love or capitalism we should thank for this happy state, but it's not genetics.

ANDREW P READ

\section{Ceroid-Lipofuscinoses. Batten Disease and Allied} Disorders

Edited by J M Opitz, R K Pullarkat, J F Reynolds, and L M Spano. (Pp 308; \$85.00.) New York: Alan R Liss. 1988.

A literary weekly recently ran a competition in which readers had to suggest a book title of such stupefying obscurity that not a single copy would be sold. As I recall, the winning title was $A$ history of the theory of rain. The title of this book would surely have run a close second at least; it is quite easy to find distinguished professors of genetics who have never heard of the ceroid-lipofuscinoses let alone seen a case. The contents of this excellent volume are a marvellous illustration of how misleading the title and cover (dull green) of a book can be.

It is an account of the proceedings of the International Conference on Ceroid-Lipofuscinoses held on Staten Island, New York over two years ago (May 1987). As such it is a model of how such proceedings should be produced: impeccably illustrated, organised, and edited. The ceroid-lipofuscinoses are probably the most common of the neurodegenerative disorders of childhood. The common phenotype is exceptionally cruel in its relentless and devastating effect on child and family. By comparison cystic fibrosis seems almost the work of a benign providence. In spite of 20 years of intensive investigation its biochemical basis remains a tantalising enigma. Promising theories for its causation have perished with the same inevitability as its victims.

The volume opens with an invaluable and comprehensive bibliography for the years 1970 to 1986 . The 27 papers presented at the conference have been cast as chapters arranged in four sections: Clinical and pathological studies, Animal models, Biochemical studies, and Treatment. The Riders, whose Children's Brain Disease Foundation has done so much to foster research in Batten disease, provide a useful overview of recent work and future hopes.

The individual contributions are of a uniformly high standard and range from careful accounts of long term clinical trials to some fairly abstruse biochemistry. Excellent accounts of the features of the various subtypes will fascinate the paediatric neurologist. A short but masterly account of the Newfoundland aggregate of NCL will intrigue the geneticist. Comprehensive descriptions of the several animal models available will satisfy the most demanding veterinary pathologist. An up to date review of current biochemical investigations including changes in lymphocyte membrane fluidity, cathepsin B activity measurements, and alterations in dolichol linked oligosaccharides will mystify all but the most erudite biochemists. The accounts of the various ingenious approaches to treatment are models of careful and cautious interpretation.

Inevitably the delay in publication engendered by production of such high quality conference proceedings dictates that the latest work and approaches to this disease are not discussed. Identification of the proteolipid subunit of ATP synthase as a 
component of the storage material (R D Jolly and coworkers) is an exciting new advance. At least two groups of researchers are applying linkage analysis using DNA markers in an effort to map the disease gene or genes.

This volume is a must for anyone involved with the ceroid-lipofuscinoses at the bedside or in the laboratory. For any paediatric neurologist, geneticist, biochemist, or pathologist with only the haziest notions concerning this group of diseases, perusal will make you the local expert and provide the best introduction to one of the most intriguing enigmas in medicine.

\section{R M GARDINER}

\section{Recent Advances in Ectodermal Dysplasias}

Edited by C F Salinas, J M Opitz, and N W Paul. (Pp 295; \$96.00.) New York: Alan R Liss. 1988.

This book consists of the papers presented at a symposium sponsored by the Society of Craniofacial Genetics in 1985. As such, the topics chosen represent the personal interests of the authors; the quality and quantity of content and presentation is variable.

In the first section (Nosology and basic science), I found two papers of interest. Holbrook's contribution on the histological and ultrastructural study of the early development of skin and its appendages was valuable; Jorgenson and others discussed techniques for studying palmar sweat pore density.

In the next section (Clinical manifestations), there were 10 papers. Opitz discussed several congenital anomalies, in which a dysplasia manifesting in embryonic or fetal life may have caused ectodermal and other anomalies to develop as a sequence rather than a series of primary malformations. Freire-Maia and Pinheiro describe in outline the clinical appearance of 15 ectodermal dysplasias (EDs) described since their 1984 book went to press. Gorlin reviews some interesting EDs with hearing loss. Levin provides a helpful description of the oral abnormalities in a number of EDs.

In addition to these reviews, there were also contributions on the clinical features of single ED syndromes. One very useful paper described two extensive Rapp-Hodgkin families, and extended the reported spectrum of manifestation of this disorder. Other papers described a restrictive dermatopathy, one form of autosomal recessive hypohidrotic ED (HED), and a trichothiodystrophy in which the hair shaft is dystrophic and there may be an underlying metabolic disorder amenable to chemical analysis. The paper on cephalometry in $\mathrm{X}$ linked HED reported only very preliminary results; it seems that this technique is unlikely to help diagnose carrier status. The paper on speech in HED makes the non-contentious assertion that dentures help children with hypodontia to articulate with clarity.

The third section (Management) is polysyllabic, but low on content. There are hortatory comments on team care and regionalisation, on the advantages of early diagnosis, and on the benefits of visiting a dentist if you have few teeth. One useful tip is included: that nasal crusting can be helped by sniffing water or saline into or through the nasopharynx. Tanner discusses the emotional adaptation of those with ED syndromes to their disorder and the effect on the family as a whole. This is a difficult topic, with no easy answers.

This book will be of interest to two groups. The reviews and the scientific papers will interest those with a very special interest in the ectodermal dysplasias. Gorlin's review and the papers describing Rapp-Hodgkin disease and trichothiodystrophy will also interest some dysmorphologists. Only very few will want a personal copy, but access to a library copy of this volume might be helpful for dysmorphologists and for paediatric dentists interested in genetics. 